\title{
APONTAMENTOS SOBRE MODOS DE SER (E NÃO SER) MUSEU DE ARTE CONTEMPORÂNEA EM PORTO ALEGRE
}

\author{
Bianca Knaak ${ }^{\text {* }}$ \\ Universidade Federal do Rio Grande do Sul
}

RESUMO:

Ao longo dos 20 anos do Museu de Arte Contemporânea do Rio Grande do Sul, as tomadas de posição de seus gestores, apoiados na valorização de seu acervo, incidiram fortemente nas características da coleção que - museu mantém. Destacando momentos dessa história identificamos a representatividade de seus agentes $e$ os modos de ampliação, visibilidade e legitimação desse museu, desde a sua criação.

PALAVRAS-CHAVES:

Museu de Arte Contemporânea do Rio Grande do Sul, Acervo, Exposição, Representação Social, Legitimidade sistêmica.

\begin{abstract}
:
During 20 years of the Rio Grande do Sul Contemporary Art Museum, positions taken by its managers, sustained on the appreciation of its collection, acted heavily on the characteristics of the museum collection. In highlighting moments of this history we identified the representativity of its agents and the ways of expansion, visibility and legitimacy the museum since its creation.
\end{abstract}

\section{KEYWORDS:}

Rio Grande do Sul Museum of Contemporary Art, Collection, Exhibition, Social representation, Systemic legitimacy.

\footnotetext{
I * Bianca Knaak é Doutora em História e Mestre em Artes Visuais pela Universidade Federal do Rio Grande do Sul onde é professora e pesquisadora. Coordena o Grupo de Pesquisa em Estudos Sistêmicos da Arte que investigaestratégias de institucionalização e promoção da arte brasileira contemporânea através de curadorias, bienais, grandes exposições, projetos museológicos e intervenções em espaços públicos. Membro do Comitê Brasileiro de História da Arte atua também como curadora, crítica e artista sazonal. Entre 1999 e 2002 dirigiu o Instituto Estadual de Artes Visuais e o Museu de Arte Contemporânea do Rio Grande do Sul.
} 
Notadamente nas últimas duas décadas, tanto quanto as bienais, os museus de arte invadiram o mundo. Sob o ímpeto da globalização econômica, com pessoas e riquezas em trânsitos, deslocamentos e itinerâncias globais, as exposições e museus de arte contemporânea também se revelaram atrações potencialmente turísticas. Hoje, muitos são verdadeiros cartões postais na geografia das artes. Alguns, com prédios imponentes, ou nem tanto, fazem da arquitetura seu atrativo principal. Outros, com acervo pequeno ou até mesmo sem nenhum, mantém sua programação com exposições temporárias. $\mathrm{E}$, claro, há os que conseguem destaque tanto pelas coleções que detém, quanto pelo prédio que as abriga. Isso sem falar das curadorias reveladoras e internacionalmente afirmativas ensaiadas em tantos museus e lugares.

Muito embora também os museus de arte tenham surgido para preservar e exibir o que já se perdia com os avanços da cultura e da tecnologia no século 18, em tese, num museu de arte, coleções e exposições se restringem a objetos de arte e seus equivalentes documentais. Instituições modernas paradigmáticas para a memória, apesar das especificidades de cada um, as definições e objetivos dos museus variaram pouco nos dois últimos séculos. Desconheço algum que, em relação ao seu objeto fim, não inclua o compromisso com a preservação, ampliação, exibição, promoção e estudo de seu acervo, ou despreze a interface valorativa da identidade cultural local, regional e internacional. Além disso, atuando a partir dos discursos e interesses do presente, todo museu também ensaia a história, ao configurar o passado com suas coleções e exposições. $O$ que nos faz pensar, em Porto Alegre, sobre as competências (e a potência) das instituições museais de hoje.

Neste texto apontarei o que considero revelador do funcionamento sistêmico do campo artístico e, ilustrativo, politicamente recorrente e distintivo na breve história do Museu de Arte Contemporânea do Rio Grande do Sul. Pois, no manejo de circunstâncias, ao longo dos anos do museu, seus gestores e colaboradores, tomaram posições que incidiram fortemente nas características do museu e das demandas públicas que o mantém².

Na cidade de Porto Alegre existem dois museus públicos de arte: o Museu de Arte do Rio Grande do Sul Ado Malagoli, o MARGS, e o Museu de Arte Contemporânea do Rio Grande do Sul, o MAC/RS. Encaminhando políticas de gestão capazes de estabelecer com eficácia a função social e cultural de um museu de arte, ambos investem em bem resolver a equação museológica que implica colecionar, exibir, estudar e conservar um acervo. Desafio permanente e justificado, afinal, o acervo de um museu é, ou ao menos deveria ser, o seu coração, sua razão, sua identidade.

Não obstante, no currículo desses dois museus estatais encontraremos muitas demonstrações da falta de políticas e investimentos para o fortalecimento de iniciativas museológicas mais efetivas, algumas vezes até mesmo mais profissionais. O MARGS, por exemplo, nascido nos anos 1950, desde 1974 ocupa um belo prédio de quase cinco mil metros quadrados (construído em 1913 e tombado pelo IPHAN em 198I). Ao longo de quase 20 anos, no entanto, esse museu peregrinou por espaços provisórios que incluem uma

2 Nesse artigo reviso e amplio o conteúdo de minha comunicação no XXXI Colóquio do Comitê Brasileiro de História da Arte, em Campinas, na Unicamp, em 201 I (KNAAK, 201 I). 
casa de molduras, onde fez sua exposição inaugural ${ }^{3}$ e o foyer de um teatro (o Teatro São Pedro). Já o Museu de Arte Contemporânea gaúcho, inquilino da Casa de Cultura Mario Quintana, há exatos 20 anos espera por uma sede apropriada para suas funções.

No sul do Brasil, como em outras regiões do país, a prosperidade do Museu de Arte Contemporânea do Rio Grande do Sul não se equipara aos seus congêneres internacionais. Fundado em 1992, sua presença museal nesse cenário cartografado é questionável e, nas rotas nacionais, sua localização ainda é institucionalmente difusa, quase invisível. Mesmo assim, e apesar de suas referências nacionais serem o MAC-USP (1963) e os Museus de Arte Moderna do Rio de Janeiro (1943) e de São Paulo (1948), podemos incluir o surgimento do MAC/RS (1992) no rol de museus de arte criados sob o entusiasmo multicultural global aliado às expressões artísticas pós-modernas dos anos 1980 e 1990.

Tendo como pano de fundo uma conjuntura macroeconômica e artística internacional, o MAC/RS abriu suas portas com uma grande exposição de artistas atuantes na cena contemporânea. Entusiasmados com a idéia de um novo museu, os artistas doaram obras que foram sendo reunidas para o MAC/RS antes mesmo de sua fundação. Movido por um otimismo pioneiro, o museu nunca mais parou de promover, receber e colecionar obras doadas.

Assim, comemorando seus 20 anos o MAC/RS promove intensa revisitação do seu acervo (e trajetória) com exposições em diferentes espaços da cidade de Porto Alegre. Analisadas em conjunto, essas exibições acentuam a recorrente estratégia de resistência do museu através da afirmação valorativa de sua coleção. Ao marcar a data com várias exposições (recuperações e incorporações) do acervo, o museu provoca frentes de discussão e revisão de suas políticas de sobrevivência institucional, entendidas como formas de colaboração para pensar o que significa, na esfera pública, um museu de arte. Em particular, o que o MAC/RS significa, hoje. É nesse sentido que seguem as reflexões aqui apresentadas.

II

O MAC/RS foi criado pelo decreto estadual $n^{\circ} 34.205$, publicado em 04 de março de 1992. "A Exposição Inaugural - Núcleo de Acervo”, inaugural e propulsora, foi aberta no dia 18 de março do mesmo ano, na Galeria Sotéro Cosme da Casa de Cultura Mario Quintana (CCMQ). Lugar designado para abrigar provisoriamente o novo museu de arte e onde, no entanto, ele permanece até hoje.

Ao longo dos anos, ocupando um pouco mais, um pouco menos de espaços cedidos ${ }^{4}$, o MAC/RS sobreviveu saltitando entre os andares da Casa de Cultura Mario Quintana onde atualmente acomoda seu pequeno acervo, o diretor e duas funcionáriás. Resistindo junto àquele complexo cultural, ele dispõe, para exposições, das galerias Sotéro Cosme e Xico Stockinger e do vão livre de circulação entre elas, chamado Espaço Vasco Prado (de onde foi

3 ntitulada "Arte Brasileira Contemporânea", a primeira exposição do MARGS ocorreu em 1955. Na Casa das Molduras, apresentou obras de 33 pintores, entre eles, Portinari, Di Cavalcanti, Schaeffer, Iberê Camargo, Petrucci, Trindade Leal e Ângelo Guido. Todos estes integrantes de seu acervo.

4 O que incluiu uma malograda tentativa de transferência para o Cais do Porto, a partir de exposições coletivas realizadas entre 2004 e 2006. 
retirada a escultura em bronze de Vasco (“Modelo em Repouso", 1988), que fazia jus ao nome dado àquele vão no $6^{\circ}$ andar).

A função social do MAC/RS, segundo seus estatutos, está em "pesquisar, preservar, divulgar um acervo de arte contemporânea regional, nacional e internacional e desenvolver propostas educativas". Mas, sem espaço físico nem corpo funcional suficientes, desde a sua criação, o museu segue precário junto ao tímido circuito artístico regional.

No entanto, se a atenção nas políticas de gestão é basilar para que um museu possa representar e se comunicar com suas comunidades e, embora 0 acervo do MAC/RS (ou mesmo do MARGS) não tenha visibilidade num circuito ampliado, desenvolver essa instituição vem sendo pauta em sucessivos programas de governo. Mas a fragilidade institucional do MAC/RS é, também, um reflexo dos objetivos e das políticas culturais em voga ao longo dos anos em nosso estado e país. Sem clareza do lugar e da função desse museu na estrutura administrativa e cultural do Estado, seus representantes serviram-se da indefinição programática do MAC/RS para, a partir dela, encaminhar e chancelar ações e eventos conforme a agenda preferida.

Essa indefinição há muito fragiliza a autonomia institucional do museu. $\mathrm{E}$ isso repercute em manifestações, às vezes desconcertantes, sobre o que fazer no "vazio" que espaços como o MAC/RS deveriam preencher institucional-

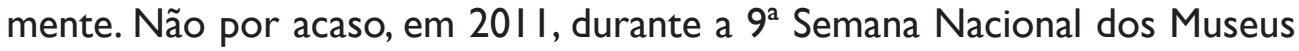
em Porto Alegre, José Nascimento Júnior, presidente do Instituto Brasileiro de Museus (IBRAM), destacou que "o que realmente faz falta na cidade da Bienal do Mercosul é um centro de arte contemporânea de ponta digno da produção artística do Estado" (NASCIMENTO, 20I I). Ciente das vicissitudes que assolam o museu desde 1999, quando ele mesmo dirigia o Museu Antropológico do RGS e o Sistema Estadual de Museus e parceiro de primeira hora dos movimentos para a viabilização de uma sede para o MAC/RS, é de se supor que ele se referia à situação do MAC/RS.

Ainda sobre isso, é ilustrativo que apenas ao completar 20 anos esse museu, até então amparado por doações periódicas, faça sua primeira compra de obras para o acervo. Financiada via leis de incentivo à cultura, em 2012 essa aquisição representará a integração de $2 \mathrm{I}$ obras de artistas brasileiros à sua coleção, através do Prêmio Marcantonio Vilaça concedido pela FUNARTE. Juntamente com outras iniciativas oportunas, frente à data de aniversário do museu, essa seleção pode tanto reiterar modos de colecionamento institucional quanto ajudar a redefinir a lógica do Museu de Arte Contemporânea do Rio Grande do Sul e seus modos de ampliação do seu acervo.

III

Nos anos 1990, visando à formação de uma coleção substancial para fundamentar a criação do MAC/RS, o Instituto Estadual de Artes Visuais (IE$\mathrm{AVI})$, dirigido pelo artista Gaudêncio Fidelis, deu início ao processo de incorporação de obras com o chamado Ciclo Arte Brasileira Contemporânea - CABC 5 . O Projeto vigorou de 199I a 1994 e, a cada exposição, os artistas eram convidados a doar uma obra para o futuro MAC/RS. Mesmo sendo uma

5 Segundo Fidélis (2007) o CABC foi inspirado no "Ciclo Perspectivas Recentes da Escultura Contemporânea Brasileira", do Instituto Nacional de Artes Plásticas da FUNARTE, e no "Ciclo de Instalações" do Centro Cultural São Paulo. 


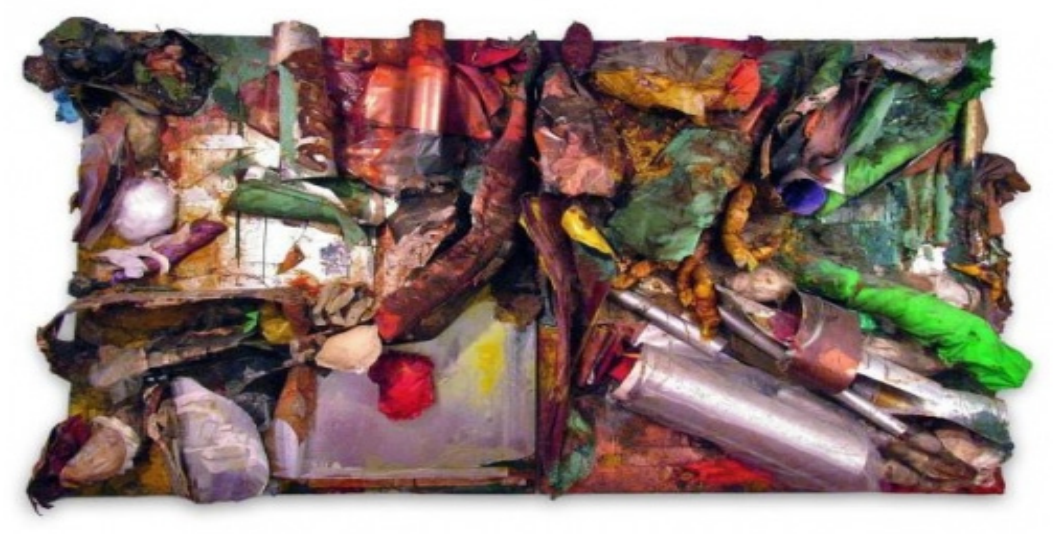

Imagem I - Nuno Ramos. Sem título, 1991. 240 × 400 cm.

Vários materiais sobre madeira.

Doação do artista para o acervo MAC/RS.

Fonte: Ramos (|99|).

doação compulsória, numa espécie de contrapartida aos custos de produção e divulgação de cada mostra, a adesão dos artistas foi generosa e imediata.

Nesse período houve a realização de exposições de artistas locais e mostras que mesclavam obras do acervo do MARGS e do MAC, com nomes emergentes (como ocorreu em "Décadas de Consolidação - Arte Brasileira no Acervo do MARGS") e também exposições individuais, como, por exemplo, Nuno Ramos (imagem I), Jac Leirner,Angelo Venosa,Vera Chaves Barcellos, lole de Freitas, Karin Lambrecht, Carlos Fajardo e Marco Giannotti. Dessa programação, em 1993, o IEAVI já havia reunido cerca de 100 obras para o MAC/RS.

Para Fidelis (20I I), a coleção do novo museu teria início prioritariamente com a produção da década de 1990 e, ao longo de sua construção, poderia se expandir a partir dos anos 70. Produções anteriores a essa data deveriam ficar para o MARGS. Esse entendimento deu rumo à coleção do MAC/RS, que já se estabelecia com as ações anteriores à fundação do museu propriamente dito, e também teve consequências no perfil institucional apresentado em seus primeiros anos de atividade.

Veremos que, recém-inaugurado, o MAC/RS protagonizou uma série de ações e programações que permitiram o mapeamento da produção artística no Estado ("Sistema de Curadorias Regionais") e também a receber artistas de destaque na cena contemporânea nacional. Como foi o caso de Nuno Ramos que, já renomado, e em sintonia com o espírito do novo museu, realizou a impactante instalação II I (sobre o massacre dos apenados do Carandiru) pela primeira vez na Galeria Sotéro Cosme do MAC/RS.

Ao longo dos anos de teimosa intenção de existência, outras exposições, como as individuais de Joseph Beuys, Regina Silveira, Baselitz, Carlos Scliar, Lenir de Miranda e Otto Dix, por exemplo, renovaram o elã de atuação e consolidação desse espaço público para a arte contemporânea e também estabeleciam parcerias institucionais produtivas.

Entendendo acervo e museu como instâncias indissociáveis, mesmo com sua pequena coleção, desde cedo o MAC/RS realizava mostras sob recortes específicos. Essa prática fazia o acervo respirar e inspirar a cena local. Sob essa motivação note-se que as esculturas do acervo vieram a público, juntas, em 1993 para a mostra “Anti-corpo”; em 1994 esculturas e objetos foram des- 
tacados para tratar da "Desmaterialidade Metódica"; em 1996, numa montagem com objetivos didáticos, o acervo buscou obras para "Expressão e Construção"; em 2000 as gravuras do acervo fizeram a mostra "Arte sobre Papel"; em 2001 o MAC/RS mostrou a "Figura na Pintura"; em 2007 foi a vez de "Mulheres no Acervo do MAC” e, em 2009, a coleção exibida evidenciou "O Papel no Acervo do MAC".

As montagens de investigação da coleção ajudavam a manter o museu vivo. $O$ alcance e a qualidade dessas iniciativas promocionais do acervo e de ativação cultural trouxeram reconhecimento ao museu. Assim que, já em 1994, o MAC/RS emprestava as obras de Karin Lambrecht e Carlos Fajardo para integrar a mostra "Bienal Brasil Século XX”, em São Paulo.

IV

Não é difícil localizar exemplos de museus que, para contornar deficiências de acervo e se manterem atraentes para um público heterogêneo, acabem transformados em centros de exposições temporárias. Além disso, frente à falta de políticas públicas e ações propositivas, não é raro perceber que a agenda de um museu, sendo estatal, seja vulnerável a interferências de associações de artistas, corporações acadêmicas e outras clientelas ${ }^{6}$. Afinal, todo museu, resultado direto de políticas culturais e, por vezes, de ideologias indiretas, por sua função simbólica representa uma conquista social. E, como tal, enseja disputas, agenciamentos e tomadas de posição permanentemente.

$\mathrm{Na}$ história do MAC gaúcho, ao que parece, a sustentação sócio-simbólica do museu está no envolvimento do meio artístico pela valorização de um acervo inexorável. Não fosse assim, não faria nenhum sentido que, em 201 I, o recém-empossado diretor do MAC/RS, André Venzon (artista e ex-presidente da Associação Riograndense de Artes Plásticas Francisco Lisboa) declarasse ao jornal que "o museu existe mesmo sem uma sede, sem um espaço permanente, porque temos as obras [...] e precisamos reconhecer esse acervo" (VENZON, 20I I, p. 2).

Sabe-se que o acervo do MAC/RS foi angariado entre entusiastas de um museu propositivo em construção e, mesmo com poucas obras (menos de 400 peças em 20I I), nomes importantes da cena contemporânea nacional estão ali bem representados. Sem uma sede e reserva técnica condigna, o problema que se alastra, no entanto, diz respeito à própria razão de ser de um museu. Se na prática - MAC/RS ainda é, material e simbolicamente, apenas o seu acervo, como é possível conhecer ou reconhecer acervo/museu que não tem onde nem como ser exibido e estudado com rigor? A falta de registros documentais substanciais, como atas e relatórios, projetos, catálogos e fotos, que indiciem o encaminhamento e os trâmites necessários à realização das esporádicas exposições do acervo (imagem 2) é, no mínimo, sintomática da inviabilidade do museu como espaço de pesquisa e conhecimento artístico, patrimonial e histórico.

\section{V}

Um projeto várias vezes repensado, o MAC/RS ainda é um projeto intermitente. Seu projeto inaugural, sem ter sido de todo abandonado, também nunca foi totalmente instituído, junto a Secretaria de Estado da Cultura e à sociedade, pensada como um circuito maior de beneficiários e contribuin-

6 Sem falar na fragilidade dos conselhos consultivos frente à subordinação político-partidária dos Cargos em Comissão (CC's), como são os cargos de direção dos museus estatais. 
tes. E os percalços ao longo dos anos de atuação do MAC/RS, considerando outras instituições artísticas, encontram ressonância na história de seus pares nacionais que padecem pela ausência de recursos estruturais capazes de integrá-los ao que chamamos de sistema das artes visuais.

Cabe lembrar que, em 2005, o crítico carioca e conselheiro da Fundação Iberê Camargo, Paulo Sergio Duarte, assinava a curadoria geral da $5^{\text {a }}$ Bienal de Artes Visuais do Mercosul, acompanhado pelos gaúchos Gaudêncio Fidelis, como curador adjunto, Neiva Bohns (ex-conselheira e curadora convidada do MAC/RS) e José Francisco Alves ( $2^{\circ}$ diretor do MAC/RS, atual curador-chefe do MARGS), como curadores assistentes. Naquele momento, segundo observação de Duarte, não existiam museus de arte em Porto Alegre. Pois, de acordo com sua definição,

Um museu tem que ser pelo menos $40 \%$ visível; $60 \%$ seriam sua infra-estrutura, laboratórios e reservas técnicas. Segundo esses critérios são pouquíssimas as instituições no Brasil que poderiam chamar-se 'museus' e, seguramente Porto Alegre ainda não tem nenhum (DUARTE, 2006, p. 8I).

Mesmo sendo menos exigente, o criador do MAC/RS reclama de gestões ineficientes. Segundo Fidelis, "enquanto o MAC for administrado por amadores não haverá solução para os problemas da instituição" (FIDELIS, 2007, p. 37). No entanto, se administrar implica em planejamento competente a curto, médio e longo prazo, no MAC/RS a fragilidade se mostra congênita. Seu projeto inaugural subestima a falta de um endereço próprio e omite as fontes de seu financiamento.

Se, ao longo da trajetória sempre descontínua e insurgente do museu houve um planejamento paralelo, que respondesse as essas questões, ele evidentemente não se confirmou. Por sua vez, recordando o período inicial do MAC/RS, em entrevista inédita Fidelis esclarece:

Quando assumi o IEAVI no Governo Collares não havia um projeto
de governo para criar o museu. Este era um projeto meu, que eu de-
senvolvi naquele primeiro ano dentro do IEAVI. Não havia promessa
para a sede, embora eu achasse que o museu teria a sua sede em
breve se continuássemos naquele ritmo de trabalho. Eu honesta-
mente não sei por que há tanta dificuldade em conseguir uma sede
para o museu? (FIDELIS, 20II)

VI

À falta de um prédio próprio e a pouca visibilidade do acervo soma-se a inconstância de planejamento curatorial e, logo, percebemos como, em diferentes momentos de sua história, o MAC/RS falha na salvaguarda de seu patrimônio artístico, não estimula o conhecimento, nem o colecionismo e, sequer, funciona como indicador para o fomento de um mercado regional. No entanto, sob condições de funcionamento em que as atividades de rotina equilibram o precário e o provisório, o museu se mantém orgulhoso com um acervo que foi destaque em exposições importantes, mas ainda assim, continua quase invisível em sua relevância. Na prática, podemos dizer que este MAC ainda é uma intenção de museu e, politicamente, com muito a se fazer em seu favor. 


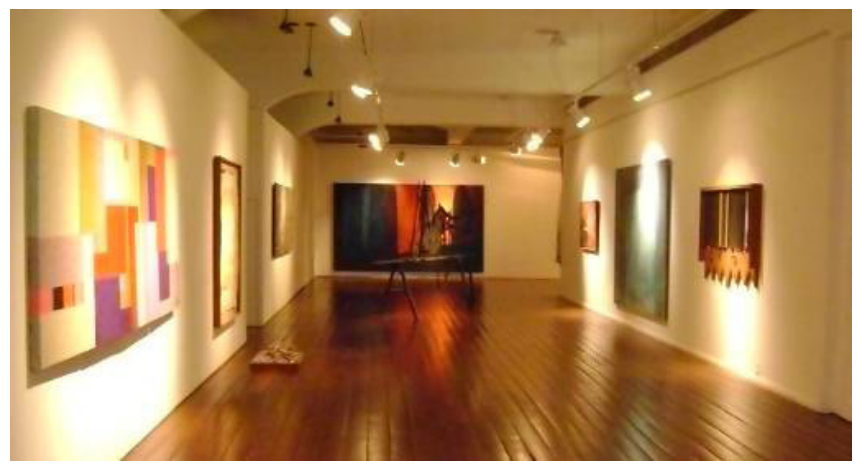

Imagem 2 - Vista parcial da mostra "Acervo MACRS", na Galeria Sotéro Cosme da CCMQ

de fevereiro a maio de 20II. Com obras de Paula Mastroberti,

José Francisco Alves, Vera Wildner, Marilice Corona,Vera Chaves Barcellos,

Alphonsus Benetti, Rogério Prestes de Prestes, Michael Chapman, Udo Kunert

e Marco Giannotti (na parede ao fundo).

Fonte: A autora.

Assim sendo, é dessa precariedade (e com ela) que se estabelecem os valores culturais e os agentes protagonistas da cena contemporânea (artística e institucional) local. Desde a escolha dos diretores e a composição de seus conselhos consultivos, deliberativos ou curador, que atuam, coletiva ou individualmente, na seleção de artistas convidados a expor ou doar obras ao MACl RS, a formulação de editais de ocupação de seus espaços e na proposição de parcerias interinstitucionais, muitos são os atores que se destacam junto à comunidade como assíduos mentores do perfil e das atividades do museu.

O Museu de Arte Contemporânea do Rio Grande do Sul, por sua vez, carrega um passado de dificuldades cumulativas. Sua acomodação sempre provisória e a alta rotatividade de seus diretores ( 10 em 20 anos) já foram apontadas ora como causa, ora como consequência da sua claudicante atuação. Seu histórico não só evidencia disputas políticas e partidárias como também obriga o museu a se reinventar continuamente, a cada gestão.

O MAC/RS protagonizou atuações (boas e nem tanto) surpreendentes nesses 20 anos de r(existência). E atravessou algumas crises.

Aos olhos do grande público, o problema maior do MAC/RS sempre foi salvaguardar sua coleção, coisa que, cedo, ameaçava a continuidade do museu. Apenas dois anos depois de inaugurado, segundo denúncia pública do já $3^{\circ}$ diretor do MAC/RS, Fábio Coutinho, 14 obras haviam desaparecido, supostamente por inépcia e omissão de seus antecessores. Das 147 obras, descritas em atas de reuniões, termos de doação e livro tombo, faltariam gravuras e desenhos dos artistas Ivan Serpa, Regina Silveira, Marilice Corona, Maria Tomaselli e Roberto Schmidt-Prymm.

Amplamente divulgado pela imprensa local, esse fato acabou desencadeando uma sequência de acusações, sindicâncias, condenações e processos que, por fim, foram arquivados por insuficiência de provas. Mas o infortúnio fez com que o MAC/RS perdesse 14 obras de sua coleção. $E$, ainda às voltas com o desaparecimento das obras e os graves problemas de conservação do acervo, em 1995 seu $4^{\circ}$ diretor, José Luiz do Amaral, questionava, pelo jornal, se o Estado do Rio Grande do Sul poderia arcar com os compromissos de um Museu de Arte Contemporânea. Publicamente, foi a primeira vez que se fez essa pergunta. Respondê-la talvez não encerre a problemática do MAC/RS, mas com certeza implica em revisões políticas e ideológicas. 
O MAC/RS protagonizou atuações (boas e nem tanto) surpreendentes nesses 20 anos de $r$ (existência). E atravessou algumas crises.

Em 1999, com apenas sete anos, e num de seus momentos mais críticos, os problemas oriundos da insuficiência de instalações físicas e de uma equipe profissional, entre outras de ordem administrativa, comprometiam seu desempenho e imagem pública. $O$ desprestígio constatado incluía obras desaparecidas, acervo mal conservado e períodos de inatividade. Naquele contexto se impunha como ponto pacífico, na opinião geral, a necessidade de uma sede para amparar o museu e dar prosseguimento ao seu projeto inaugural. E o lugar desejado pelos artistas e agentes culturais era um armazém, às margens do Guaíba, no Cais do Porto da capital (imagem 3).

Dirigi o MAC/RS e o Instituto Estadual de Artes Visuais do Rio Grande do Sul (IEAVI) 7 de outubro de 1999 a janeiro de 2002. Nesse período, enquanto fazíamos (direção e conselheiros do IEAVI e do MAC/RS) os movimentos políticos e administrativos necessários para a conquista de uma sede apropriada junto ao Cais do Porto, geramos um modo de apresentação pública que dissociava a atuação cotidiana, plausível e visível do museu, das suas pretensões programáticas.

Nesse modo de apresentação, um era o “MAC real”, percorrendo espaços múltiplos e eventuais, onde as pessoas se encontravam com as obras do acervo e de outros artistas a cada exposição. Outro era o "MAC utópico", onde buscávamos a concentração e o encontro de esforços políticos e administrativos que construiriam, junto às instâncias necessárias, os recursos e dispositivos capazes de amparar, num futuro breve, o Museu de Arte Contemporânea do Rio Grande do Sul no Armazém A6 do Cais do Porto.

À época, tentando contornar sua fragilidade e para evidenciar a gravidade da situação, em diferentes circunstâncias o MAC/RS revisitou e organizou mostras do seu acervo. Com essa prática, curiosa e concomitantemente em sua trajetória, observa-se que, se é sobre seu acervo que se abatem as maiores chagas museais, é também deste patrimônio que o museu vem extraindo os bálsamos curativos de sua manutenção e função social. Sobretudo porque, apesar de pequena para a sua idade, a coleção do MAC/RS abriga boas obras.

Assim, também nós entendíamos, quando à frente do MAC/RS que, embora desfalcado e sem condições de crescer, o acervo precisava ser exposto, para justificar a existência do museu. Então, num ato pioneiro e de grande risco patrimonial, a partir de 1999, parte do acervo percorreu o interior do Estado, inaugurando com o "MAC real" uma política de descentralização e interiorização.

Paralela e simultaneamente, as exposições itinerantes, na Galeria Sotéro Cosme, o MAC/RS abrigava exposições do acervo e de artistas locais, nacionais e internacionais, como Alfredo Nicolaiewsky (imagem 4), Anico Herskowitz, Carlos Wladimirsky, Karin Lambrecht, Mario Röhnelt, Regina Ohlweiller

7 Órgão criado em 1990 e vinculado a Secretaria da Cultura, para coordenar ações relacionadas às artes visuais promovidas pelo governo e aquelas desenvolvidas pelo MARGS, pelo MAC e pelos Centros de Desenvolvimento da Expressão; promover intercâmbios com outros centros do país e do exterior; promover a integração entre a produção de artes visuais e setores educacionais do Estado e a ampliação dos circuitos, divulgação e incentivo à manifestação artística de novos talentos, bem como a pesquisa e documentação sobre artes visuais no Rio Grande do Sul. 
(“Artistas Convidados - 1999”), Rubem Grilo (“A Arte Menor”) Gil Vicente ("Desenhos"), Jorge Ferro e Georg Baselitz. À época, parcerias institucionais e pequenas curadorias garantiram a maior parte das exposições em Porto Alegre que, bem produzidas e divulgadas, renovavam o interesse do público, mas eram, no entanto, insuficientes para a consolidação estratégica do museu.

Inquilino da Casa de Cultura Mario Quintana e dependente de suas decisões administrativas, o MAC/RS se viu obrigado a interromper suas atividades em diversas ocasiões. Como ocorreu em 200I, quando a CCMQ, entraria em obras para conservação e foi por isso fechada ao público. Por conseguinte, o museu também foi obrigado a fechar. Com isso, às vésperas de seu $10^{\circ}$ aniversário, o $\mathrm{MAC/RS}$ estava interditado, sem previsão de reabertura e desamparado, política e financeiramente, até mesmo para realizar projetos alternativos.

Naquele momento, em busca do "MAC Utópico" (com instalação no Cais do Porto já confirmada pelas autoridades competentes: municipais, estaduais e federais) e a pedido de Gaudêncio Fidelis, em 200I, consenti que fossem restauradas, pelos próprios artistas, as obras de Nuno Ramos (imagem I) e a pintura de Marco Giannotti, "Fachada em Azul e Vermelho", (óleo sobre tela, 1994) dentro da galeria Sotéro Cosme. Tratava-se do programa de restauro de obras fundantes do acervo do museu, vinculado à pesquisa de Fidelis para o seu livro "Dilemas da matéria - procedimento, permanência e conservação em arte contemporânea" (2003). E, enquanto o MAC/RS permanecia fechado, em 2002, já sob a direção de seu $7^{\circ}$ diretor, Décio Presser, foi restaurada a obra "Colunas" (bronze, aço inoxidável, cobre e latão, 1994), de lole de Freitas.

Sem autonomia financeira nem dispondo de rubrica específica, no "MAC real" as dificuldades começavam com a falta de uma reserva com condições efetivamente técnicas para guardar sua coleção e desdobravam-se em debilidades operacionais e de manutenção, até as mais ordinárias, como substituir lâmpadas queimadas ou cadear uma porta arrombada. Por tudo isso, e principalmente sem condições de tratar o acervo adequadamente, sob minha direção, nenhuma obra foi incorporada à coleção do MAC/RS.Além do mais, "inchar os depósitos de museus de doações que jamais ou pouco serão exibidas (apesar de engrandecer o currículo de alguns emergentes) não é mérito de diretor algum de museu, nem tampouco para artista algum" (AMARAL, 1999, p. 17).

Mesmo assim, ao longo dos anos, ainda que fosse um problema administrá-lo, o Museu de Arte Contemporânea do Rio Grande do Sul continuou a depositar no acervo sua principal razão de ser. Nos momentos mais difíceis, acima e antes de tudo, invocava seu compromisso institucional para com o acervo conquistado. Compromisso a ser honrado em nome dos artistas (que ainda continuam a doar obras) e da sociedade, mesmo que as condições de preservação e promoção desse acervo jamais tivessem alcançado os patamares profissionais pretendidos. 


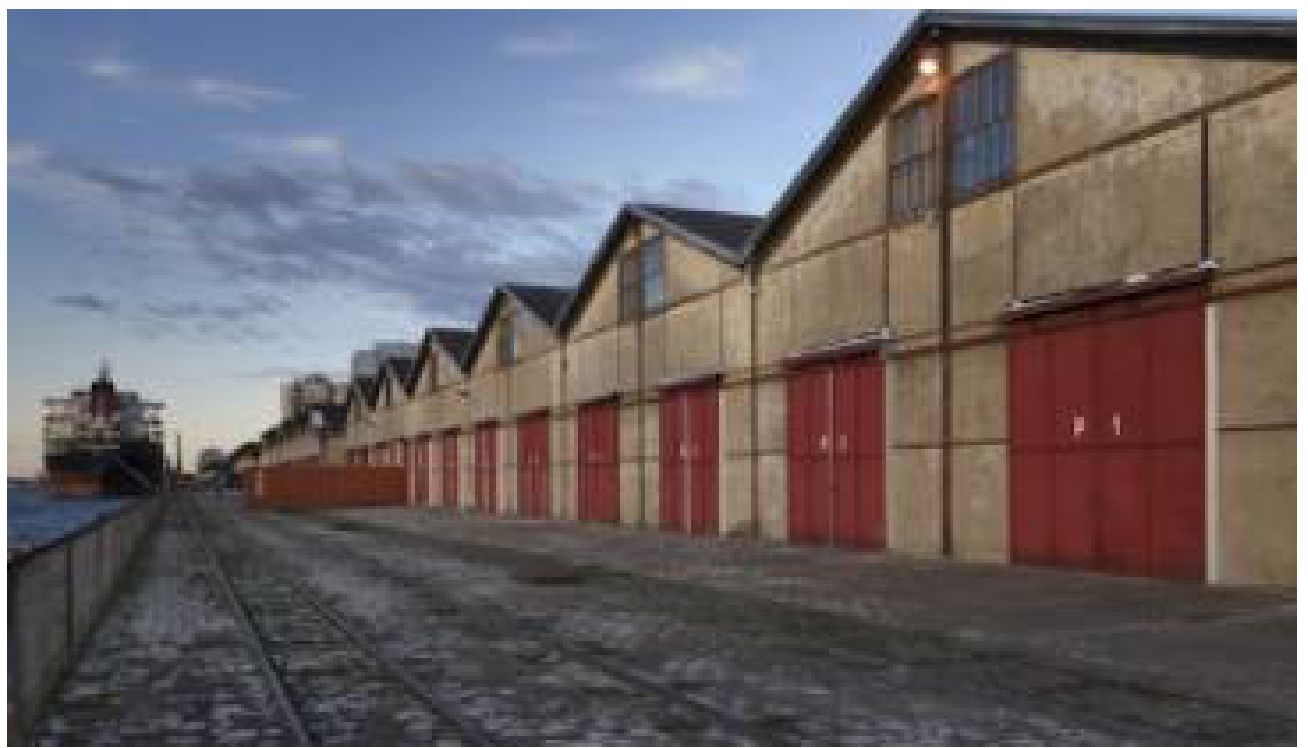

Imagem 3 - Armazéns do Cais do Porto de Porto Alegre (vista parcial).

Fonte:Aautora.
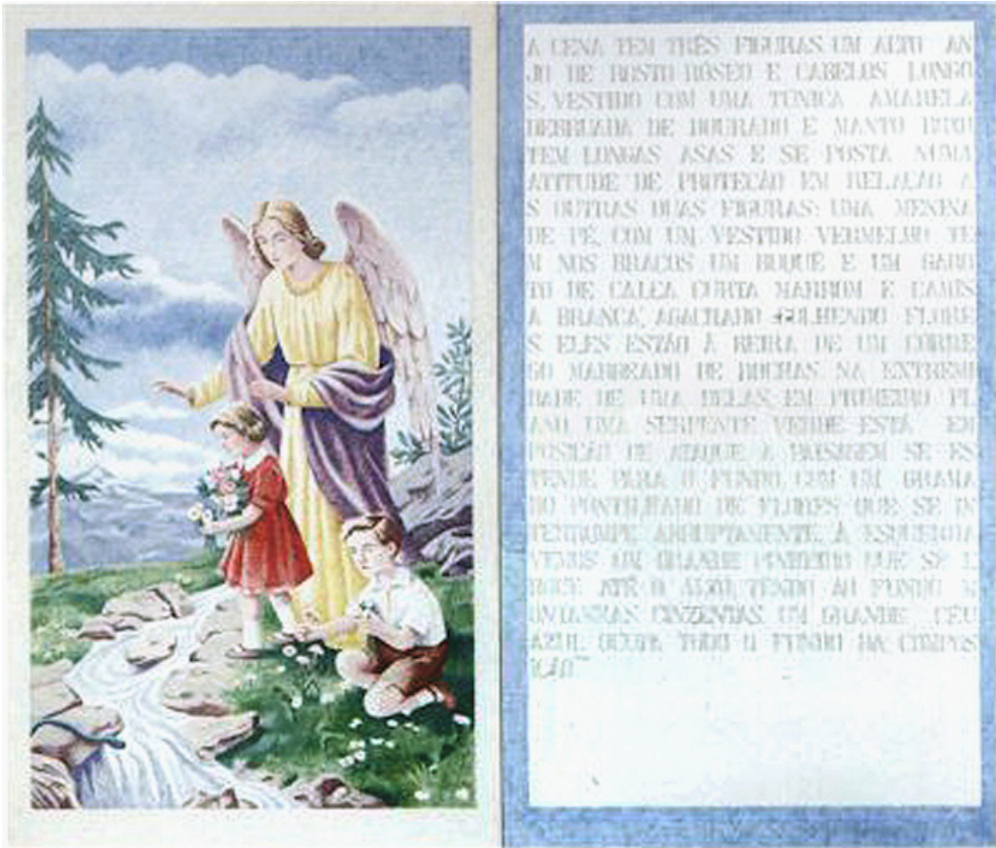

Imagem 4 - Tinta acrílica sobre tela. Díptico

exposto no MAC/RS na coletiva

"Artistas Convidados - 1999". Coleção do artista.

Fonte: Nicolaiewsky (1993/1994). 


\section{VII}

Em 1999, à condução do IEAVI e do MAC/RS, foi preciso enfrentar os limites com alguma ousadia e criatividade. Acreditávamos, inicialmente, serem provisórias as circunstâncias e confiávamos que os seus limites poderiam encaminhar ao surgimento de um novo modelo de museu para o estado. Recordo aqui uma sugestão do conselho consultivo do MAC/RS, ainda em 1999. Àquela altura, já cansados de ver a penúria continuada do museu e a paulatina deterioração de seu acervo, os membros desse conselho propuseram a criação de uma coleção "imaterial”. Na verdade, um banco de projetos de ações, intervenções e instalações efêmeras e renováveis.

Prevendo a utilização de materiais de fácil acesso, os projetos seriam desenvolvidos e assinados por artistas de diferentes partes do mundo e chegariam até o MAC/RS em resposta a uma carta-convite permanentemente aberta. Cada projeto deveria ser detalhado, com instruções suficientemente descritivas para que pudesse ser executado pela equipe técnica do museu, sempre que fosse preciso, dispensando a presença do artista e o armazenamento dos materiais utilizados a cada montagem. Claro, o projeto original permaneceria e passaria a fazer parte do acervo, bem como a documentação a ele acrescentada a cada execução, como registros fotográficos, audiovisuais, estudos e etc.

Com esse acervo conceitual vislumbrava-se, obviamente, a instauração de uma plataforma para a problematização das noções modernas de aura e autoria, assim como também de mercadoria. Apesar de acolhida pela direção do museu, a sugestão não chegou a ser executada. Entre outros motivos, paradoxalmente, por estar condicionada à curadoria dos conselheiros propositores. Estes, logo acabaram demitindo-se do conselho consultivo, desautorizando, por assim dizer, a concretização da proposta pelo museu.

A idéia, no entanto, não era original. Pelo contrário. Remonta aos anos 1960 e as experiências conceituais trazidas à tona tanto pelos artistas quanto por alguns curadores interessados nas relações processuais entre forma e conteúdos das obras e exposições. O modelo de montagem de exposição por instrução começou, provalvelmente, em 1962 com a performer Yoko Ono quando, no Sogetsu Art Center (Tóquio), ela realizou uma ação em que orientou o público à criação de obras de arte em 30 folhas de papel branco. Seguindo esse mote conceitual, dentre as exposições mais recentes podemos destacar Located Work (Madri, 2008) curada por ninguém menos que o emblemático Joseph Kosuth. Mas a maior e talvez mais conhecida dessas propostas foi a exposição 557.087, de 1969. Nesta, a crítica de arte norte-americana Lucy Lippard e mais 60 artistas enviaram instruções para realização de obras em Seattle, Washington e, noutra versão, 955.000, levaram adiante essa mesma ideia em Seattle, Vancouver e arredores ${ }^{8}$.

Para Yoko e outros artistas conceituais, incluindo brasileiros, trabalhos assim, que só veremos enquanto estiverem em processo de execução ou conheceremos por relatos verbais e imagéticos, participam da percepção estética que julga a idéia de arte mais completamente vital do que as manifestações físicas das idéias artísticas. Refletem bem o ethos dos anos 1960 e a mobilização contracultural dos artistas pela desestetização da arte, pela abolição do objeto durável e, portanto, facilmente comercializável enquanto fetiche.

8 Os títulos em números (557.087 e 955.000) representam a soma das populações desses lugares. 
Além de todos os meandros conceituais em que as obras por instrução imbricam, nesses exemplos, tanto quanto na proposta do conselho consultivo do $M A C / R S$, fica evidente que não existe remessa material de um lugar a outro. Nada além de um papel ou mensagem eletrônica circula. Ninguém precisa se deslocar para estar em muitos lugares ao mesmo tempo, o que é perfeito para um circuito internacional global da arte, conectado em rede. Além do mais, a maioria dos espaços culturais, galerias, instituições e museus não hegemônicos raramente dispõem de recursos financeiros, físicos ou estruturais para esse deslocamento continuado dos artistas e suas obras remontáveis.

IX

Para comemorar seu $20^{\circ}$ aniversário o museu preparou uma série de atividades e, enfaticamente, desvelou e revelou seu acervo em diferentes espaços expositivos da cidade, inclusive no MARGS. Lá, em abril de 2012 a mostra documental "Museumetria", organizada pelo artista, curador e ex-diretor do MAC/RS, Francisco Alves, reconstrói em textos, fotos, catálogos, convites, reportagens e outros materiais de arquivo, a história do Museu de Arte Contemporânea do Rio Grande do Sul.

Integrando uma programação extensa, nas galerias do museu junto a CCMQ, o comitê curador do MAC/RS montou de 23 de agosto a 07 de outubro de 2012 a mostra "Idades Contemporâneas". Neste conjunto de exposições curadas por Ana Zavadil ("Poéticas em Paralelo"), Paula Ramos ("Diante da Matéria"), Marcelo Gobatto e Paulo Gomes ("Corpoimagem”), e produzidas para incorporar novas doações ao museu, foram destaques a novíssima geração, o núcleo histórico da coleção e a produção em vídeo do acervo.

Mas, antes destas mostras, e já na perspectiva retrospectiva, de 10 de dezembro de 2011 a 29 de janeiro de 2012 o museu exibiu "A medida do gesto: um panorama do acervo do MAC/RS", curada por acadêmicos do Instituto de Artes da Universidade Federal do Rio Grande do Sul (UFRGS) 9 . As produções selecionadas para essa exposição, pinturas, objetos e obras sobre papel em diferentes técnicas, foram doadas ao MAC gaúcho ao longo dos seus primeiros anos e algumas peças, como a de Alexandre Antunes (imagem 5), chegaram antes da fundação do museu.

Atividade fim da disciplina Laboratório de Museografia (registrada em catálogo), a montagem favorecia leituras frutíferas desse acervo, sem malabarismos iconográficos nem apelo aos diálogos insustentáveis. A mostra exibia, na já histórica Galeria Sotéro Cosme, trabalhos de 29 artistas, a maioria gaúchos, como Eduardo Haesbaert (imagem 6), Mario Röhnelt, Frantz, Lenir de Miranda, Otto Sulzbach, Elida Tessler e Teresa Poester.

Logo em seguida, acompanhado do maior catálogo de obras do museu editado até então, o acervo também se exibiu para "O Triunfo do Contemporâneo: 20 anos do museu de arte contemporânea do Rio Grande do Sul”, de 07 de março a 22 de abril de 2012. No centro Histórico de Porto Alegre,

9 Coordenados pela professora Ana Albani Carvalho, assinam a curadoria, Carlos Eduardo Galon, Fernanda Castilhos, Laura Miguel, Leila Coffy, Luise Malmaceda, Luiza Mendonça, Mariana Patrício e Vânia Riger. Entrelinhas, há na exposição as relações de longa data entre o Instituto de Artes da UFRGS e o MAC/RS. Principal instituição de formação artística no Estado, a maioria dos artistas gaúchos na coleção do MAC/RS é ou ex-aluno ou professor do Instituto de Artes da UFRGS, ou ambos.Além disso, mais da metade de seus diretores é egresso do IA e seus professores e alguns ex-alunos são presença permanente nos conselhos consultivos e curadores do museu desde a sua fundação. 
I50 obras de 64 artistas ocuparam o andar térreo do Santander Cultural, instituição privada e vizinha do MARGS ${ }^{10}$. A mostra revisitou ao acervo e a ele introduziu dezenas de novidades sob o crivo de seu idealizador, fundador e primeiro diretor.

Com essa curadoria Gaudêncio Fidelis retomou a tarefa de curar a coleção do MAC/RS, assumindo responsabilidades que implicaram não apenas em revisar, restaurar e exibir obras fundamentais para a compreensão sensível de seu acervo, mas também de atualizá-lo com novas doações. Pois, muito embora a coleção do MAC/RS tenha se constituído pela generosidade dos artistas, como já foi dito, o museu não dispõe de uma política de aquisições programática e consistente, o que favorece desequilíbrios em sua representatividade no contexto contemporâneo.

Por outro lado, a cada lote de novas incorporações, o MAC/RS encontra oportunidades materiais, para encaminhar seu reposicionamento institucional. $O$ que inclui a incontornável necessidade de uma sede e a avaliação de sua coleção, dos rumos de seu acervo, de seu perfil artístico e ideológico.

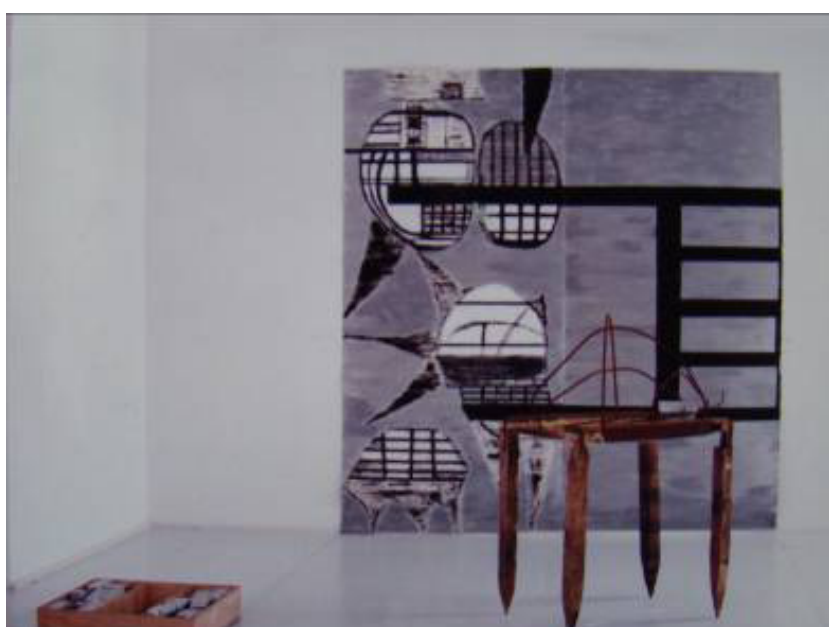

Imagem 5 - Madeira, ferro, lã de vidro e resina. $135 \times 110 \times 85 \mathrm{~cm}$ Doação do artista para o acervo MAC/RS. A esquerda caixa de madeira e pedras e, ao fundo, pintura acrílica sobre papelão, ambas do mesmo autor, em montagem na mostra "Arte Gaúcha Contemporânea”, em I99I, promovida pelo IEAVI e reapresentada nas mostras "A Medida do Gesto e O Triunfo do Contemporâneo: 20 anos do museu de arte contemporânea do Rio Grande do Sul".

Fonte:Antunes (I99I).

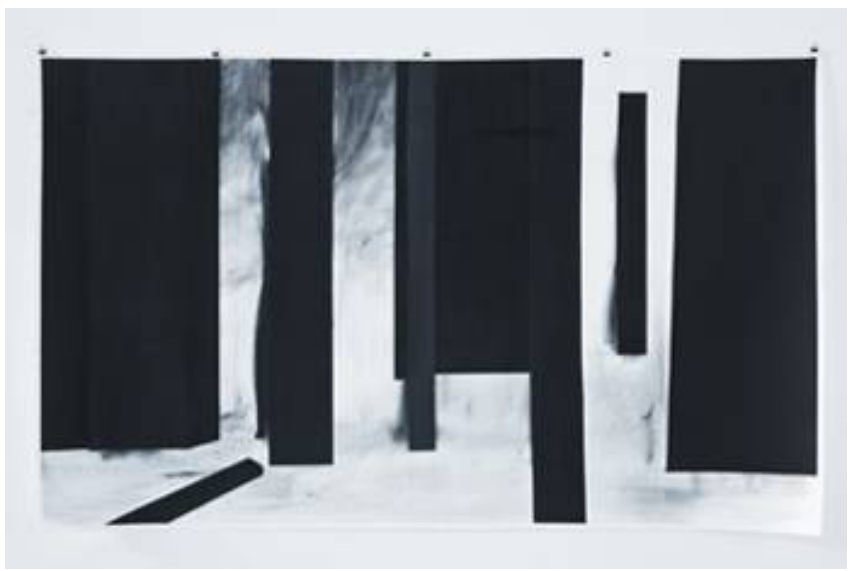

Imagem 6 - Pastel seco sobre papel. $150 \times 245 \mathrm{~cm}$

Obra integrante de "O Triunfo do Contemporâneo: 20 anos do museu de arte contemporânea do Rio Grande do Sul”. Doação do artista para o acervo do MAC/RS. Fonte: Haesbaert (20II).

10 Em diferentes momentos os caminhos do MARGS e do MAC/RS se encontram. Para esse artigo não deixa de ser curioso notar que Gaudêncio Fidelis, fundador e primeiro diretor do MAC/RS e José Francisco Alves, segundo diretor do MAC/RS, assumiram em 20I I, respectivamente, as funções de diretor e curador-chefe do MARGS, investindo na revisão e atualização do acervo dos dois museus. 
Combatendo injúrias e desencantos, foi justamente a amizade, a proximidade e a cumplicidade dos artistas com os gestores do museu que garantiram sua manutenção e representatividade social. Até por isso, a fragilidade patrimonial e política do MAC/RS se revelam também injustas para com a representatividade de seu acervo. Neste, percebe-se o compromisso com a cena regional, o que transforma o MAC/RS, em alguns momentos, numa espécie de museu comunitário. Um tipo de espaço institucional e de resistência onde, mesmo produzindo e afirmando a ordem simbólica, como explica Huyssen (1997, p. 225), "sempre haverá uma sobra de significados que excedem o conjunto das fronteiras ideológicas, abrindo assim um espaço para a reflexão e a memória contra-hegemônica".

Nessa perspectiva museica - termo utilizado por Huyssen (1997), um museu precisa encaminhar uma política de promoção artística identificada com os grupos locais, observável na especialidade de seu acervo. Mas, tratando-se de um museu de arte contemporânea, que assume o paradoxo de conservar materialmente o presente sem muitos equívocos e lacunas, o museu precisará dispor de obras de referência não apenas regionais. Nesse intuito, as exposições comemorativas aos 20 anos do MAC/RS foram boas oportunidades para que, junto da exibição promocional de seu acervo, o museu pudesse angariar novas obras que lhe permitissem inscrição e status no circuito legitimador da arte contemporânea.

$\mathbf{X I}$

As chamadas obras fundantes do acervo, aquelas reunidas pelo $C A B C$ entre 1991 e 1994, vêm se mostrando incontornáveis para a compreensão narrativa e linear do perfil desejado para a coleção do MAC/RS. Podemos observar isso cada vez que o acervo é revisitado. De tão recorrente, em 2007 o próprio Gaudêncio Fidelis foi convidado para organizar, na Galeria Sotéro Cosme, uma mostra comemorativa dos 15 anos do museu. Sob o título, “Associações livres - ler é acreditar", Fidelis reuniu então 16 artistas que considera basilares para a compreensão do perfil do acervo. Escolheu obras para evidenciar momentos específicos na trajetória do museu e que seriam partícipes de "um contexto maior".

Idealizador desse acervo, Fidelis reputa a exposição que organizou como um "empreendimento museológico" (FIDELIS, 2007). Neste, ao dispor as obras fundantes da coleção do MAC/RS com as de outros acervos, evidenciaria os acertos dessa coleção ao longo anos, considerando os rumos tomados pelos artistas ali representados.

Assumindo o tom biográfico ele declarou sua curadoria como um "ensaio para uma exposição narrada" (FIDELIS, 2007, p. 9). No catálogo virtual, seu esforço argumentativo se dava em favor da construção de uma visualidade que permitisse reconhecer que o MAC/RS é um projeto que continua coerente em sua política inicial de aquisições. A confirmação de sua avaliação pode partir de uma visita aos arquivos do museu, onde observaremos que, depois do CABC, nenhum outro projeto de aquisição foi desenvolvido com a mesma envergadura.

Segundo Fidelis (2012, p. 16) os museus precisam trazer "à luz não só as obras que têm permanecido na obscuridade das reservas técnicas, mas 
também aquelas que, por não terem recebido o devido apoio institucional, permanecem confinadas aos limites dos ateliês, sem nunca serem vistas". Nesse intuito, ao promover a visibilidade museológica à produção emergente nacional, presume-se que mais do que os riscos de uma avaliação precipitada, colecionar tais obras permitiria a consolidação de uma tradição e uma história da arte mais plural e acessível fisicamente. $\bigcirc$ que, aliás, tem sido a preocupação e o lamento de muitos historiadores, considerando a inexistência ou indisponibilidade de obras em acervos públicos para uma efetiva história da arte no Brasil.

Portanto, imbuído do compromisso institucional memorialista, em 20 I2, para "O Triunfo do Contemporâneo: 20 anos do museu de arte contemporânea do Rio Grande do Sul”, o curador solicitou doações a artistas do Rio Grande do Sul e de outros estados. Com isso a exposição pode incorporar ao acervo 59 obras de 32 artistas brasileiros, já devidamente catalogadas desde a sua exibição inaugural na coleção do MAC/RS. A terça parte desses artistas, aproximadamente, já estava representada no museu e doou trabalhos recentes a fim de preencher lacunas do acervo. Os demais, como Yuri Firmeza (imagem 7), Pablo Lobato, Tony Camargo, Sandro Ka, Orlando Maneschy, Marina Camargo, Didonet Thomaz, Gilda Vogt e Dudi Maia Rosa, estrearam na coleção do museu e a adensaram com trabalhos escolhidos pelo curador.

Mesmo com vasta programação comemorativa e valorativa de seu acervo, a falta de espaço físico apropriado ainda limita a atuação do Museu de Arte Contemporânea do Rio Grande do Sul e, principalmente, afeta seu acervo quando pensamos em necessárias expansões. Nesse sentido, a doação de Dudi Maia Rosa, torna- se um exemplo dessa necessidade. $O$ artista, que doou a pintura em poliéster, fibra de vidro e resina pigmentada ("Sem Título", 2007, 197 x 197,5 x 06 cm) trazida para "O Triunfo do Contemporâneo", esperava oportunidade desde 1992 para efetuar a doação prometida para - museu. Naquela época, quando realizou exposição integrando o CABC, a obra apresentada foi uma pintura de $17 \mathrm{~m}$ e, embora quisesse doá-la, o MAC/ RS, responsavelmente, declinou da oferta por falta de condições técnicas para acomodação do trabalho.

\section{XII}

Apesar da existência dos conselhos consultivos e curadores, as incorporações ao acervo do $M A C / R S$ pedem vigilância.A história ensina que muitos são os equívocos patrimoniais de um acervo. Mais ainda quando dependem de doações. Por isso mesmo, os museus só deveriam aceitar "doações de obras quando elas estão rigorosamente dentro da relação preparada por uma comissão técnica" (AMARAL, 1999, p. 17) do contrário, a doação pode representar "ônus para o Estado, pois toda obra que entra em um acervo significa investimento em pesquisa, conservação, preservação, divulgação" (AMARAL, 1999, p. I7).

Além do mais, não bastassem os riscos implicados na custódia das obras, até $201 \mathrm{l}$ poucos itens estavam efetivamente tombados e catalogados. Não há, portanto, um número de acervo progressivamente confiável. Em diferentes períodos, a relação oscila entre um conjunto de menos de 100 e mais de 300 peças.

E as discrepâncias desses levantamentos (refeitos a cada nova gestão), contaram sempre com ampla cobertura jornalística: mais de 100 em 1993; I47 em 1994; 99 em 1999, por exemplo, conforme reportagens locais. 
Embora não console ninguém, é revelador saber que em outros tantos museus além do MAC/RS também há muito para investir, investigar e lamentar em relação à visibilidade dos acervos de arte contemporânea no Brasil (OLIVEIRA, 20I0). Por isso, como Teixeira Coelho (ex-diretor do MAC-USP e atual curador do MASP) há quem defenda que "um museu que pretende, ou só consegue atuar como sala de exposição temporária, deveria doar seu acervo para quem pudesse mantê-lo" (COELHO, 1999, p. 27).

Ocorre que, mesmo sendo coerente, em respeito ao patrimônio público a sugestão é impraticável para uma instituição estatal. Por sua vez, a incúria e a inadimplência pública são inevitáveis quando um museu não pode preservar nem ampliar uma coleção com rigor e método. Decorre dessa inviabilidade institucional que muitas das funções sócio-educativas e culturais faltem à compleição do MAC/RS. Nele, apesar das exposições e revisões periódicas do acervo, a museologia ainda não se estabeleceu. E, sem sede apropriada, o museu em si segue incurável.

Circular, sua condição é conceitualmente densa, tendo em vista a paradoxal reunião dos princípios museicos de preservação com a precípua mobilidade e instabilidade da arte contemporânea e, ainda, a aridez simbólica de seu regime de consagração. Não obstante, o museu segue em busca de sua identidade, sua sede, seu lugar público e político.

Nesse processo de busca e ensaio, que já se configura como a dinâmica de funcionamento do MAC gaúcho, além de colecionar e exibir arte contemporânea no Rio Grande do Sul, o museu também quer ser um dispositivo experimental de práticas colaborativas, democráticas e culturalmente gregárias. Contudo, livre de parâmetros estabilizadores concretos, físicos e conceituais, nossa instituição-coleção amadurece, encontra, desmonta e reinventa seu modo de ser e não ser museu.

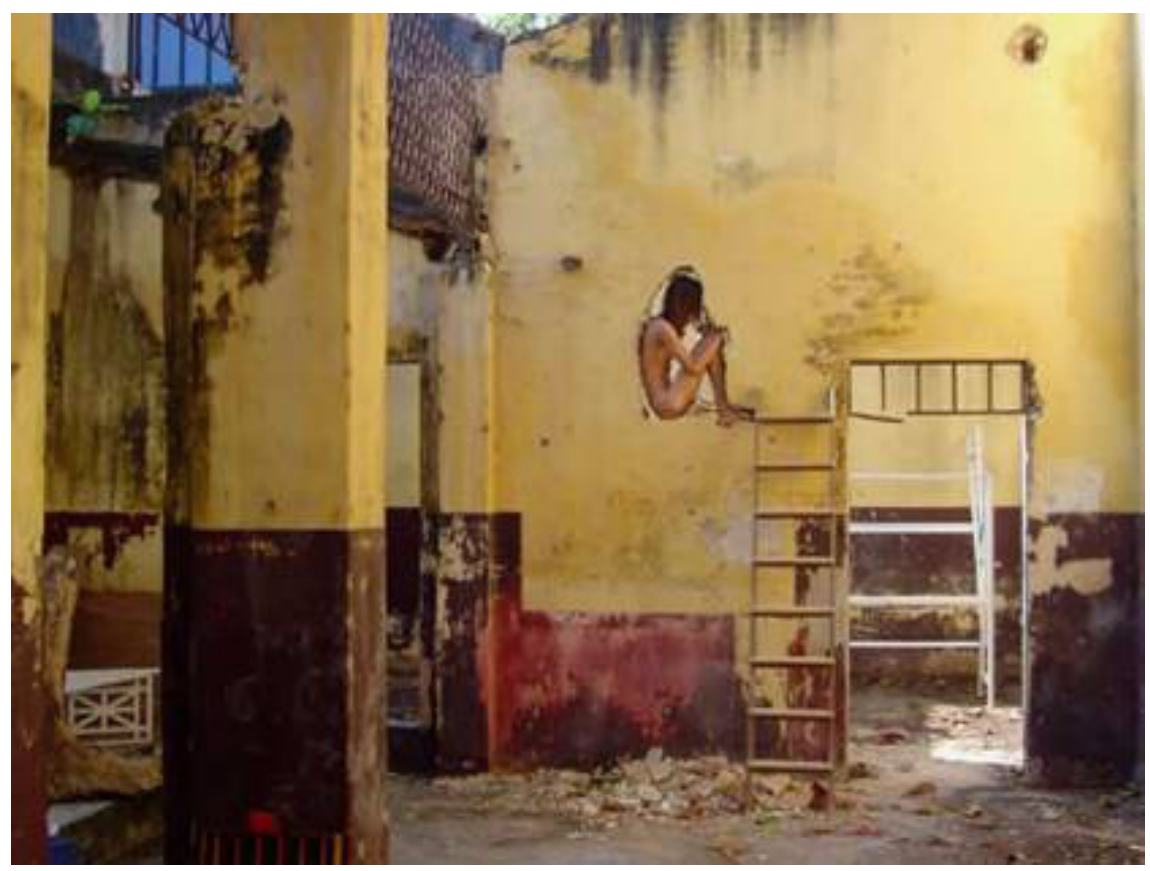

Imagem 7 - Fotografia-performance. $70 \times 92 \mathrm{~cm}$. Edição de 10 (detalhe).

Fonte: Firmeza (2005). 


\section{Referências}

ALVES JR, Dirceu. Uma década de problemas expostos: museu de arte contemporânea do Estado completa dez anos sem ter sede própria e fechado para o público. Jornal Zero Hora, Porto Alegre, 05 mar. 2002. Segundo Caderno, capa. AMARAL, Aracy. 500 anos de carência. In: SEMANA DE MUSEUS DE SÃO PAULO ACERVOS MUSEALIZADOS: REALIDADES E DESAFIOS, 2., 1999, São Paulo.Anais... São Paulo: Pró-Reitoria de Cultura e Extensão Universitária da USP, 1999. p. I5-2I.

ANTUNES, Alexandre. [Sem título]. 1991. I fotografia.

COELHO NETTO, José Teixeira. Para um museu contemporâneo de arte. In: SEMANA DE MUSEUS DE SÃO PAULO ACERVOS MUSEALIZADOS: REALIDADES E DESAFIOS, 2., 1999., São Paulo. Anais... São Paulo: Pró-Reitoria de Cultura e Extensão Universitária da USP, 1999. p. 27-30.

DUARTE, Paulo Sergio. Depoimento. In: SEMINÁRIO CIRCUITOS LATINOAMERICANOS, CIRCUITOS INTERNACIONALES: INTERACCIÓN, ROLES Y PERSPECTIVAS, 2006, Buenos Aires. Anais... Buenos Aires: ArteBA Fundación, 2006.p. 8I.

FIDELIS, G (Org.).Associações livres: ler é acreditar. Porto Alegre: Museu de Arte Contemporânea do Rio Grande do Sul, 2007a. Disponível em: <http://www.cultura.rs.gov.br/E-BOOKAssociacoesLivres_baixa.pdf>.Acesso em: 12 mar. 201 I.

FIDELIS, G. Chega de amadorismo. Aplauso Cultura em Revista, Porto Alegre, v. 9, n. 82, p. 36-38, 2007b. Entrevista.

FIDELIS, G. Dilemas da matéria: procedimento, permanência e conservação em arte contemporânea. Porto Alegre: Museu de Arte Contemporânea do Rio Grande do Sul, 2003.

FIDELIS, G. Entrevista. Entrevistador: Bianca Knaak. [S.I.: s.n.]: 20 I I. Inédita.

FIDELIS, G. O museu transformado no outro. In: O triunfo do contemporâneo: 20 Anos do Museu de Arte Contemporânea do Rio Grande do Sul. Porto Alegre: Imago Escritório de Arte, 2012.

FIRMEZA,Yuri.Ação 3. 2005. I fotografia.

GONÇALVES, Lisbeth Rebollo. Plano diretor do Museu de Arte Contemporânea da Universidade de São Paulo aprovado pelo Conselho Administrativo em 9 de junho de 1997. In: SEMANA DE MUSEUS DE SÃO PAULO, I., 1997, São Paulo.Anais... São Paulo: Pró-Reitoria de Cultura e Extensão Universitária da USP. 1997, p. 17-26.

HAESBAERT, Eduardo. Floresta concretada. 20 I I I fotografia.

HUYSSEN,A. En busca del futuro perdido: cultura y memoria en tiempos de globalización. México D.F: Fondo de Cultura Económica, 2001.

HUYSSEN,A. Memórias do modernismo. Rio de Janeiro: Editora UFRJ, 1997.

KANITZ, Mônica. Cultura no cais no Porto: vai rolar polêmica. Jornal do Comércio, Porto Alegre, II mar. 2002. Panorama, capa.

KNAAK, Bianca.Arte e sistema: um museu na medida do possível. Jonal Zero Hora, Porto Alegre, 17 dez. 201 I. Cultura, p. 03.

KNAAK, Bianca. O MAC do Rio Grande do Sul: um museu que resiste (existe?). In: COLÓQUIO DO COMITÊ BRASILEIRO DE HISTÓRIA DA ARTE, 31 ., 20I I, Campinas, SP.Anais... Campinas, SP: Universidade Estadual de Campinas, $20 \mathrm{I}$ I. 
KNAAK, Bianca. Pro tempore: uma idéia contemporânea de museu de arte em exposição. Revista do Atelier Livre da Prefeitura de Porto Alegre, n. 6, p. I0-I2, jul. 2012.

MUSEU de arte contemporânea realiza mostras itinerantes pelo interior do RS. Gazeta Mercantil, Porto Alegre, 08 fev. 2000. Cultura, p. 6.

NASCIMENTO Jr. Estado tem maior número de museus por habitante do país. Jornal Zero Hora, 20 maio 20I I. Disponível em: <http://zerohora.clicrbs. $\mathrm{com}$.br/rs/geral/noticia/20 I I/05/estado-tem-maior-numero-de-museus-por-habitante-do-pais-33 I7774.html>.Acesso em: 25 ago. 20 I I. Entrevista.

NICOLAIEWSKY,Alfredo.Anjo da guarda. 1993/1994. I fotografia, $175 \mathrm{~cm} \times 200 \mathrm{~cm}$ OLIVEIRA, E. D. G. de. Museus de fora: a visibilidade dos acervos de museus de arte contemporânea no Brasil. Porto Alegre: Zouk, 2010.

PARA restaurar uma ex-obra de arte. Jornal Zero Hora, Porto Alegre, 08 ago. 200 I. Caderno 2, contracapa.

RAMOS, Nuno. [Sem título]. 199I. I fotografia, $240 \mathrm{~cm} \times 400 \mathrm{~cm}$.

RIO GRANDE DO SUL. Decreto ${ }^{\circ} 34.205$, de 04 de março de 1992. Disponível em: <http://www.al.rs.gov.br/Legis/M0 I0/M0 I00099.ASP?HidTipo=TEXTO\&Hid_ TodasNormas $=16032 \&$ hTexto $=\& H i d \_I D N o r m a=\mid 6032>$. Acesso em:28 jul.20 I I . RIO GRANDE DO SUL. Secretaria de Estado da Cultura. Instituto Estadual de Artes Visuais. Anuário IEAVI 2000. Porto Alegre, 2000.

RIO GRANDE DO SUL. Secretaria de Estado da Cultura. Instituto Estadual de Artes Visuais. Mostra itinerante do acervo do MAC. Porto Alegre, 1999.

VENZON, André. O Mac em busca de casa própria. Jornal Zero Hora, Porto Alegre, 08 jan. 201 I. Cultura, p. 02. Entrevista.

VERAS, Eduardo. O Estado em busca das obras perdidas: catorze desenhos e gravuras desapareceram do acervo do Museu de Arte Contemporânea entre 1992 e 1994. Jornal Zero Hora, Porto Alegre, 03 abr. 1995. Segundo Caderno, capa. 